OPEN ACCESS

Edited by:

Ali Reza Oveisi,

Zabol University, Iran

Reviewed by:

Sarah Farrukh,

National University of Sciences and

Technology (NUST), Pakistan

Amarajothi Dhakshinamoorthy, Madurai Kamaraj University, India

*Correspondence: Martino Di Serio diserio@unina.it

Specialty section:

This article was submitted to

Catalytic Engineering,

a section of the journal

Frontiers in Chemical Engineering

Received: 08 July 2020 Accepted: 24 September 2020

Published: 23 October 2020

Citation:

Russo V, Hmoudah M, Broccoli F, lesce MR, Jung O-S and Di Serio M (2020) Applications of Metal Organic Frameworks in Wastewater Treatment:

A Review on Adsorption and

Photodegradation.

Front. Chem. Eng. 2:581487.

doi: $10.3389 /$ fceng.2020.581487

\section{Applications of Metal Organic Frameworks in Wastewater Treatment: A Review on Adsorption and Photodegradation}

\author{
Vincenzo Russo ${ }^{1}$, Maryam Hmoudah ${ }^{1,2}$, Francesco Broccoli ${ }^{1}$, Maria Rosaria lesce ${ }^{1}$, \\ Ok-Sang Jung ${ }^{3}$ and Martino Di Serio ${ }^{1 *}$ \\ ${ }^{1}$ Department of Chemical Sciences, University of Naples Federico II, Naples, Italy, ${ }^{2}$ Chemical Engineering Department, \\ An-Najah National University, Nablus, Palestine, ${ }^{3}$ Department of Chemistry, Pusan National University, Busan, South Korea
}

The growing accumulation of emerging contaminants in the environment can cause direct and indirect water pollution that puts human lives at risk. The fact that these contaminants are not or cannot be eliminated from the municipal water utilities, poses a significant concern. Researchers are currently pulling massive attention to improve existing technologies, develop new strategies, and provide environmentally durable solutions to mitigate water contamination problems. Adsorption and photodegradation are two of the most sustainable technologies that are used in water purification. These technologies have many advantages because of the economic, simple, and easily operated designs needed to treat wastewater. Within these applications, metal organic frameworks (MOFs) are playing a significant role as novel class of porous materials characterized by a crystalline structure. MOFs are considered good candidates to be employed in wastewater treatment technologies because of the tunability of their features. The scope of this review article is to provide a comprehensive description of the recent studies published in the literature about the adsorptive and photocatalytic use of MOFs for the removal of organic emerging contaminants from wastewater. Furthermore, this study briefly highlights the synthesis technologies of MOFs. Finally, future perspective and challenges associated with MOF large-scale production are discussed.

Keywords: metal organic frameworks, MOFs, emerging contaminants, adsorption, photodegradation, wastewater treament

\section{INTRODUCTION}

In the last few decades, much attention has been devoted to emerging contaminants (ECs), a new class of water pollutants, including natural and synthetic chemicals and their transformation products, e.g., personal care products, pharmaceutical compounds, and endocrine-disrupting products. The presence of these ECs in wastewater is considered an environmental issue due to the consequent verified toxicity for water ecosystems and health (Rodriguez-Narvaez et al., 2017). On the other hand, these products are not commonly monitored in the environment (Tran et al., 2018). Other emerging contaminants in the environment are nanomaterials, perfluorinated compounds, pesticides, industrial chemicals, surfactants, flame retardants, disinfection byproducts (DBPs), artificial sweeteners (Richardson and Kimura, 2017), etc. These contaminants come from 
many different sources, such as industrial, municipal, and hospital wastewater treatment plants (WWTP), sewer leakage, landfill leachate, etc. (Rasheed et al., 2019). Typical wastewater treatment processes do not adequately remove ECs (Ryu et al., 2014; Tran et al., 2018). Although their concentration in the environment is low, ranging from $\mathrm{ng} / \mathrm{L}$ to $\mu \mathrm{g} / \mathrm{L}$, these compounds are pseudo-persistent due to their continuous discharge (Fairbairn et al., 2018). This creates the risk of chronic exposure for living organisms, especially due to pharmaceuticals. The adverse effects of the interaction of ECs with living organisms include alteration of animal endocrine systems, reduced fertility and fecundity, and masculinization of females and feminization of males (Ruhí et al., 2016). Moreover, continuous discharge of antimicrobial agents and antibiotics can lead to the development of antibiotic-resistant bacteria, thus, reducing the effectiveness of these compounds against pathogens (Rodriguez-Narvaez et al., 2017). Richardson and Ternes investigated in their biennial review the recent developments and the current issues about ECs (Richardson and Ternes, 2018). They highlighted the presence, analysis, and the fate of different ECs in the environment. In addition, they presented the acceptable levels of ECs in water that are regulated by the World Health Organization (WHO) for water quality (Dhakshinamoorthy et al., 2019).

Water treatment technologies can be divided into biological treatment, phase changing, and advanced oxidation processes (Cheremisinoff, 2007). The most common technologies for biological treatment of waste waters involve the use of activated sludge in aerobic or anaerobic conditions; phase-changing processes are based on the sorption of the contaminant from the aqueous phase to the surface of a porous solid material (adsorbent); advanced oxidation processes (AOPs) are based on in situ formation of non-selective, highly oxidizing radicals to degrade the contaminant molecules. Investigation and development of water treatment technologies, which are effective for the abatement of this class of contaminants, are imperative to ensure the use of safe water and reduce environmental damage (Crini and Lichtfouse, 2019). Research is very active in the development and performance improvement of new nanomaterials, which could be employed as nanosorbcats (ElQanni, 2017).

In the last two decades, attention has been drawn to an innovative class of porous materials, known as metal organic frameworks (MOFs). These compounds have been first synthesized by Yaghi et al. (1995) and investigated for numerous applications in wastewater treatment (Hasan et al., 2012; Seo et al., 2016; Wu et al., 2016; Akpinar and Yazaydin, 2017; Martinez-Costa et al., 2018; Daliran et al., 2020; Hu et al., 2020), gas purification (Trickett et al., 2017), light capture and energy conversion (Kreno et al., 2012), separation processes (Yaghi et al., 2019), drug delivery (Rojas et al., 2019), and catalysis (Dhakshinamoorthy et al., 2019; Yang and Gates, 2019; Wang Z. et al., 2020). The structure of MOFs consists of metal centers and organic linkers to form infinite crystalline networks (Butova et al., 2016; Yang and Gates, 2019). These organic and inorganic hybrid structures can be categorized into metal carboxylate frameworks, metal azolate frameworks, and MOFs, including hydrophobic functionalities.
These compounds are characterized by a crystalline structure with a great flexibility in pore size, pore shape, functionality, thermal stability, and high surface area (Eddaoudi et al., 2000; Farha et al., 2012; Han et al., 2016). Such features grant their versatility in sustainable removal of various contaminants (Hasan and Jhung, 2015).

Several reviews summarized the different applications of MOFs in wastewater purification (Furukawa et al., 2013; Dhakshinamoorthy et al., 2018; Kumar et al., 2018; Mon et al., 2018; Bedia et al., 2019; Rego et al., 2020; Wang Q. et al., 2020). However, MOF real industrial applications were not thoroughly investigated and assessed (Kumar et al., 2018). These structures pose some drawbacks that can be critical in the industrial utilization in water treatment, i.e., the intrinsic instability could limit the practical performance of MOF as they may collapse in aqueous environments (Rego et al., 2020).

The main focus of this study is to review the most recent technologies in employing MOFs for the adsorptive and photocatalytic removal of emerging contaminants in wastewater streams. This is achieved by identifying the actual gaps and the state-of-the-art trends in the scientific literature in this promising research field.

\section{ABATEMENT TECHNIQUES}

Many different processes are reported recently for the abatement of ECs as shown in Figure 1. These effective technologies are (1) advanced oxidation processes, (2) phase-changing processes including adsorption in different solid matrices and membrane processes, and (3) biological treatment.

The main features of the mentioned technologies are listed below, as an example for ibuprofen removal.

- Biological Filtration: water containing low levels of ibuprofen were treated with a biologically active granular activated carbon (GAC) filter unit, managing to reduce the concentration to below the limits of quantification $(<1 \mathrm{ng} / \mathrm{L})$ (Vieno et al., 2007).

- Membrane separation: this kind of process has been proven to be effective in eliminating ibuprofen from water sources. Removal rates ranged between 92 and 99\% using nanofilter (NF) and reverse osmosis (RO) membranes with different hydrodynamic ratios and starting ibuprofen concentrations (Xu et al., 2005).

- Ozonation: one bench-scale study conducted on various sources of wastewater found that the ibuprofen removal rate ranged from 40 to $77 \%$, varying as a function of organic carbon concentration and $\mathrm{pH}$ (Nakada et al., 2007). Two other bench-scale studies gave very different results, one reported an average of $80 \%$ removal for four spiked surface waters (ozone concentration range: $2.5-4 \mathrm{mg} / \mathrm{L}$ ) (Huber et al., 2003), and another one reported $12 \%$ removal in distilled water spiked with ibuprofen (ozone concentration: $1 \mathrm{mg} / \mathrm{L}$ ) (Westerhoff et al., 2005). Results from another study about contaminated surface water treatment using a pilot-scale system showed an ibuprofen removal efficiency > 89\% (Vieno et al., 2007). 


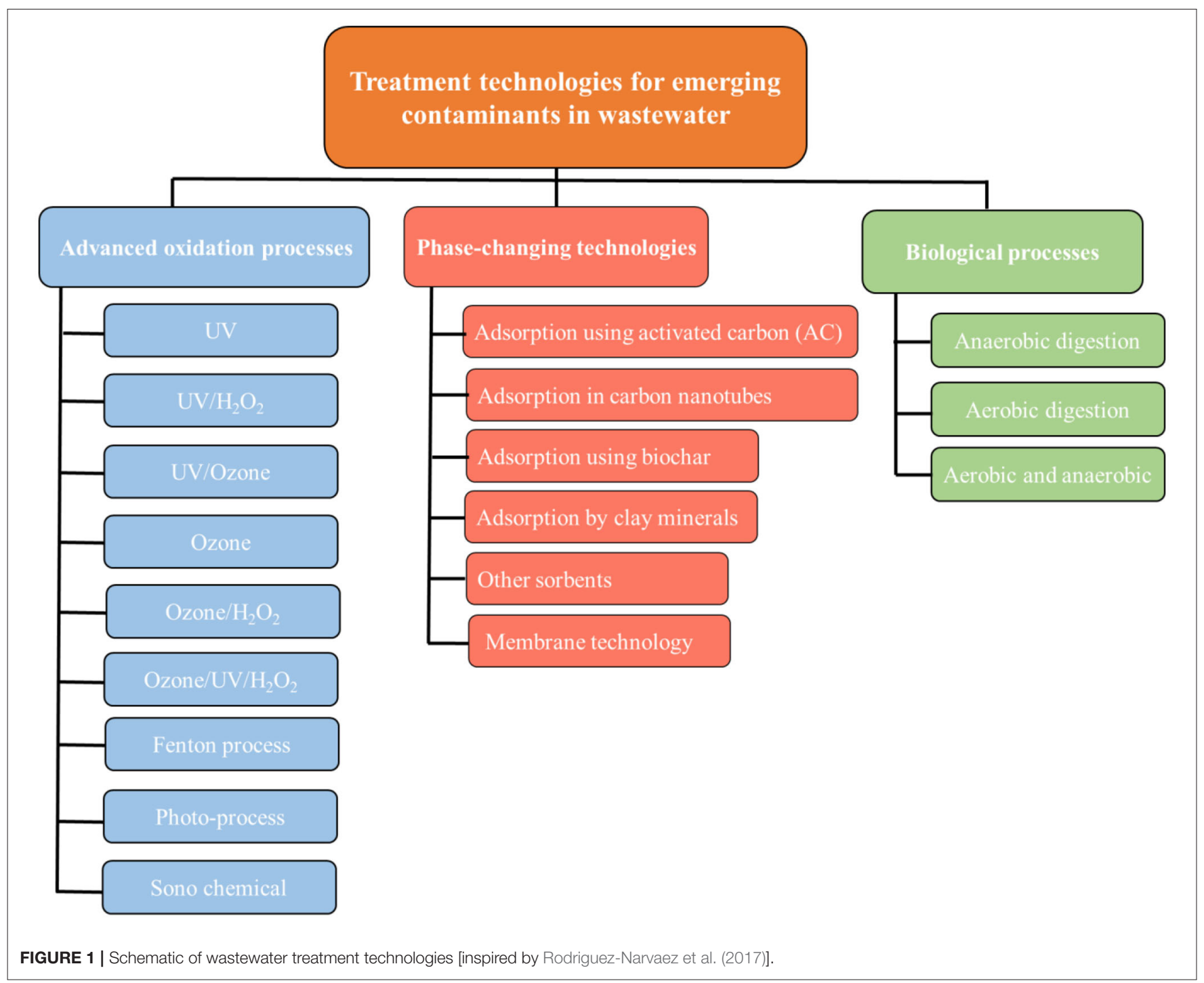

- Adsorption: removal of ibuprofen with powdered activated carbon (PAC) was reported to increase with PAC concentration. In one bench-scale study it was found that the ibuprofen removal rates ranged between 2 and $80 \%$ with varying PAC concentrations in the $1-20-\mathrm{mg} / \mathrm{L}$ range (Westerhoff et al., 2005).

- Ultraviolet (UV) radiation with an intensity designed to simulate solar irradiation was reported to cause a range of $62-67 \%$ ibuprofen photodegradation in various source waters spiked with high contaminant concentrations $(10-40 \mathrm{mg} / \mathrm{L})$ (Mohamed et al., 2018).

\section{ADSORPTION}

Adsorption is a natural phenomenon where one or more components of a fluid mixture are transferred on the surface of a solid material by physical or chemical interaction, bringing to a concentration variation compared to the adjacent phases (Russo et al., 2016, 2017). Adsorption processes are commonly employed in industrial environment for both compound separation and wastewater treatment. This technology is characterized by many attractive features, including cost effectiveness, ease of design and operation, and resistance to toxic substances. The key point of the cost analysis for adsorption technique is the cost of the employed adsorbent (Russo et al., 2016). Since the extent of adsorption greatly depends on the surface area of the adsorbent, small particles characterized by high porosity are required for industrial applications. Figure 2 demonstrates the typical mechanism of adsorption where the sorbate molecules covers the solid to form a film on the surface of the adsorbent (Lowell et al., 2004).

Good mechanical properties such as abrasion resistance are also needed for the adsorbent to be effectively used for a great number of times (Tareq et al., 2019). There are many types of adsorbents for great number of different applications. The most commonly employed adsorbents include silica, polymers, activated alumina, activated carbon, zeolites, and clay, etc. 


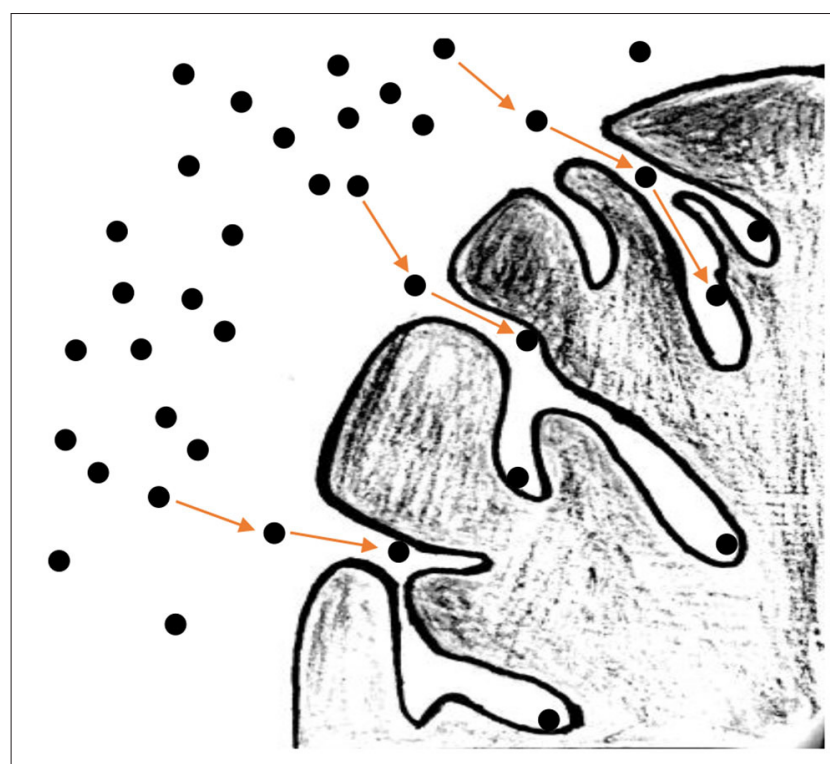

FIGURE 2 | Adsorption process schematization.

\section{PHOTOCATALYTIC DECOMPOSIION}

Advanced oxidation processes (AOPs) are a special class of wastewater treatment technologies aiming at the conversion of the pollutants to water, $\mathrm{CO}_{2}$, and inorganic substances (by mineralization). When not feasible, their conversion to smaller and harmless products is preferred. Their potential to degrade stable and bio-refractory compounds under ambient conditions makes them prominent in the field of water purification research (Gogate and Pandit, 2004). The denomination AOP comprises a large variety of different technologies, all of which involve the generation of hydroxyl radicals $(\mathrm{OH})$, which rapidly attack most organic species. The powerful, non-selective oxidative action makes AOPs suitable for the degradation of complex mixtures containing many different species (Ameta and Ameta, 2018).

Within AOPs, heterogeneous photodegradation is an interesting option for wastewater treatment compared to homogeneous processes, since the catalyst can be separated from the reaction media, and hence reused, leading to a reduction in costs and environmental issues (Poyatos et al., 2010). AOPs can be conducted either in gas or liquid phase, the latter both in aqueous and organic solutions. The process consists of five elementary steps:

1. Migration of the reactant from the liquid bulk phase to the photocatalyst surface;

2. Adsorption;

3. Surface reaction;

4. Desorption of the products;

5. Transfer of the products to the liquid bulk phase.

The catalyst is activated by photonic irradiation instead of thermal means, as it occurs with conventional heterogeneous catalysis. Heterogeneous photocatalysts are typically semiconductors (SCs) either sulfides (e.g., ZnS and CdS) or oxides (e.g., $\mathrm{TiO}_{2}, \mathrm{ZrO}_{2}, \mathrm{CeO}_{2}$, and $\mathrm{ZnO}$ ). These materials are characterized by a specific value of energy gap between conduction and valence band. A photocatalytic reaction is initiated when the catalyst absorbs a photon whose energy, $h v$, is greater than the band-gap, thus triggering a photoexcitation process. In this process, an electron $\left(\mathrm{e}^{-}\right)$is promoted from the valence band of the catalyst to its conduction band, leaving an electron hole in the valence band $\left(\mathrm{h}^{+}\right)$. At this point, electron transfer takes place from solid surface to the adsorbed acceptor (A) molecules and from the adsorbed donor (D) molecules to the solid:

$$
\begin{aligned}
& \text { Photoexcitation :SC } \stackrel{h y}{\rightarrow} e^{-\circ}+{ }^{\circ} h^{+} \\
& \text {Reduction of acceptor: }(A)_{a d s}{ }^{\circ}+{ }^{\circ} e^{-} \rightarrow A^{-} \\
& \text {Oxidation of donor: }(D)_{a d s}{ }^{\circ}+{ }^{\circ} h^{+} \rightarrow D^{+}
\end{aligned}
$$

Each ion resulting from this mechanism reacts, forming first intermediates, then final oxidation products. Figure 3 is a sketch of the AOP process.

Photoelectric energy dispersion occurs due to the electronhole recombination:

$$
e^{-}+h^{+} \rightarrow N+E
$$

where $E$ is the energy released in the form of heat or light $\left(h \nu^{\prime}\right.$ $\leq^{\circ} h v$ ), and $N$ is the neutral center resulting in a reduction of the photoexcitation process efficiency (Herrmann, 2000).

The efficiency of the photodegradation reactions generally depends upon the following operational parameters:

\section{- Irradiation intensity}

The photocatalytic reaction rate depends mainly on the quantity of photons absorbed by the photocatalyst (Curcó et al., 2002). Consequently, by increasing the light intensity, a corresponding increase in the rate of the reaction is observed.

\section{- Structure and concentration of the substrate}

These parameters influence the tendency of the substrate to adhere to the catalyst surface with higher adhesion results in a greater effectiveness of the oxidation process (Tariq et al., 2007). However, if the substrate concentration is too high, the catalyst surface becomes saturated, thus leading to a reduction of photonic efficiency and deactivation (Araña et al., 2004).

\section{- Nature and morphology of the photocatalyst}

These parameters influence the quantity of photons absorbed by the catalyst. Photocatalysts characterized by small particle size lead to higher conversion in photodecomposition of organic compounds than those with large particles (Maira et al., 2001).

\section{- Photocatalyst concentration}

The rate of heterogeneous photocatalytic reactions increases with catalyst concentration until a maximum. Further addition of catalyst causes an unwanted light scattering, hence, a decrease in the penetration of the light into the reacting solution, thus resulting in a reduction in the reaction rate 


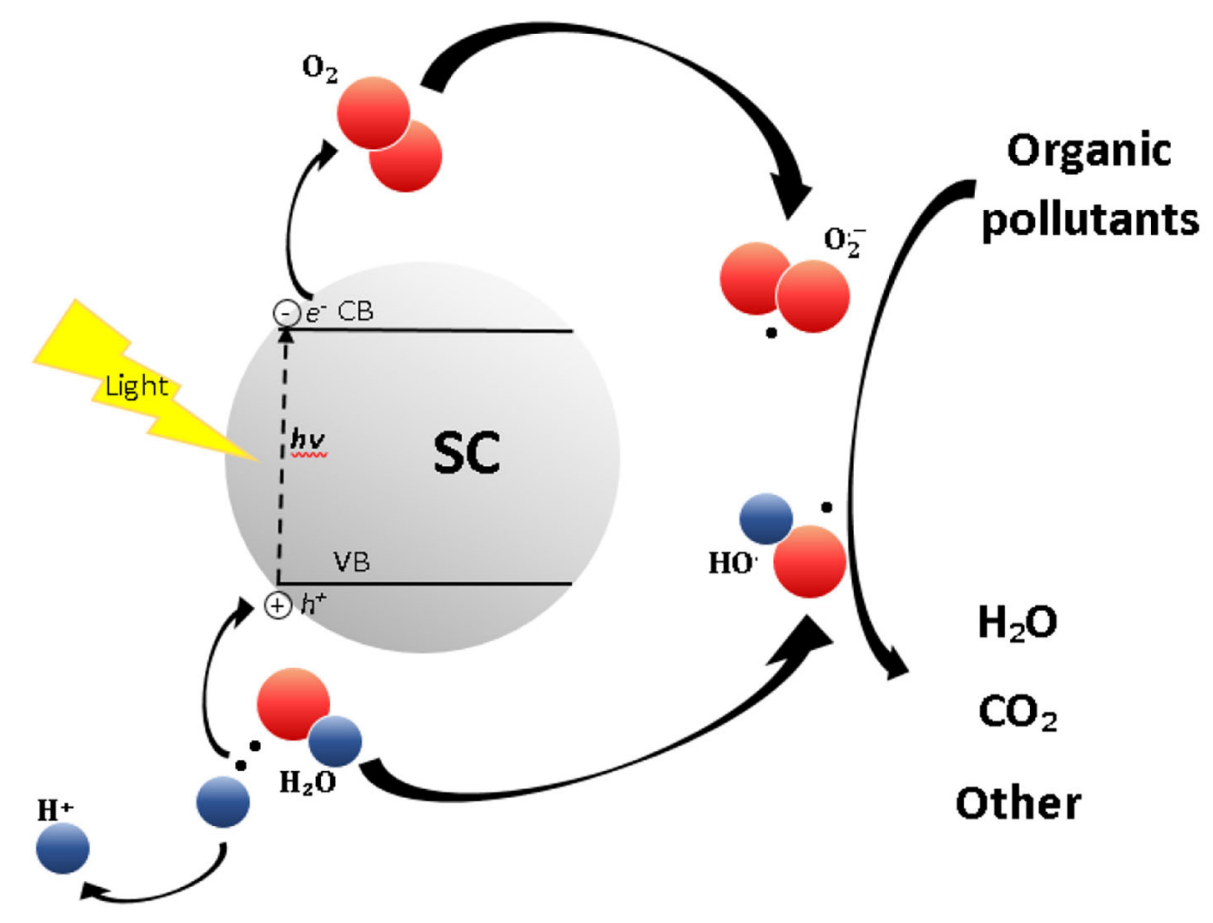

FIGURE 3 | Schematization of a photoexcitation process.

(Chun et al., 2000). This makes it necessary to determine the optimum catalyst concentration, to maximize the catalyst light absorption.

- Solution pH

The $\mathrm{pH}$ of the solution imposes properties of the surface, its charge, and, hence, the kind of aggregates that can be formed on the catalyst surface. This fact clearly influences substrate adhesion and ultimately reaction rate (Haque and Muneer, 2007).

- Temperature of the reaction

Photocatalytic systems do not require heating and work at room temperature, as the catalysts are activated by light. Heating enhances the reaction kinetics, occurring at generally a temperature range of $20^{\circ} \mathrm{C} \leq T \leq 80^{\circ} \mathrm{C}$. Above $80^{\circ} \mathrm{C}$, the adsorption of the reactants becomes disfavored, being an exothermic process, becoming the rate-limiting step of the reaction network (Alnaizy and Akgerman, 2000). At lower temperatures $\left(-40^{\circ} \mathrm{C} \leq T \leq 0^{\circ} \mathrm{C}\right)$, the activity decreases, since the rate-limiting step is the desorption of the final products (Herrmann, 2000).

For industrial applications, heterogeneous photocatalysts should be characterized by a series of characteristics, such as activity, long-term stability at high reaction conditions, poisoning resistance, attrition resistance, mechanical stability, and chemical stability. The pretreatment of the catalyst, such as calcination, sulfurization, or reduction, can influence the final activity, and/or stability of the catalyst.

\section{METAL ORGANIC FRAMEWORKS}

Metal organic frameworks (MOFs) are coordination polymers consisting of inorganic-organic hybrid frameworks showing high porosity. Their structures are composed of metal centers as connectors and organic ligands as linkers (Eddaoudi et al., 2000; Cheng et al., 2020). Figure 4A represents the MOF basic structure with organic linkers and the metal ions, and Figure 4B gives examples on the different MOFs with their corresponding metallic clusters and organic linkers (Howarth et al., 2017). The most common structures of MOFs (Qiu et al., 2014) are shown in Figure 4C.

MOFs are characterized by large pore surface area, with micro- and mesopores, and very high designability of pore shape, pore size, and surface functionality (Butova et al., 2016; Li G. et al., 2020). These properties are very promising for addressing various different challenges, which include treatment of emerging contaminants through adsorption and catalysis (Farrusseng, 2011). Currently, MOF synthesis is a very relevant topic. In 2019, the Cambridge Structural Database (CSD) reports 75,600 different structures (Moghadam et al., 2017), with the MOF types doubling every 3.9 years (Tranchemontagne et al., 2008). A search in the Scopus database for articles on MOFs gives the increased recent interest on this topic as shown in Figure 5.

There are many different methods for the synthesis of MOFs. The most common and facile route is the solvothermal method, where a mixture of metal salt is heated, and organic linkers are dissolved in a solvent, above the boiling point of the solvent itself (Yang and Bai, 2019). This method requires several 


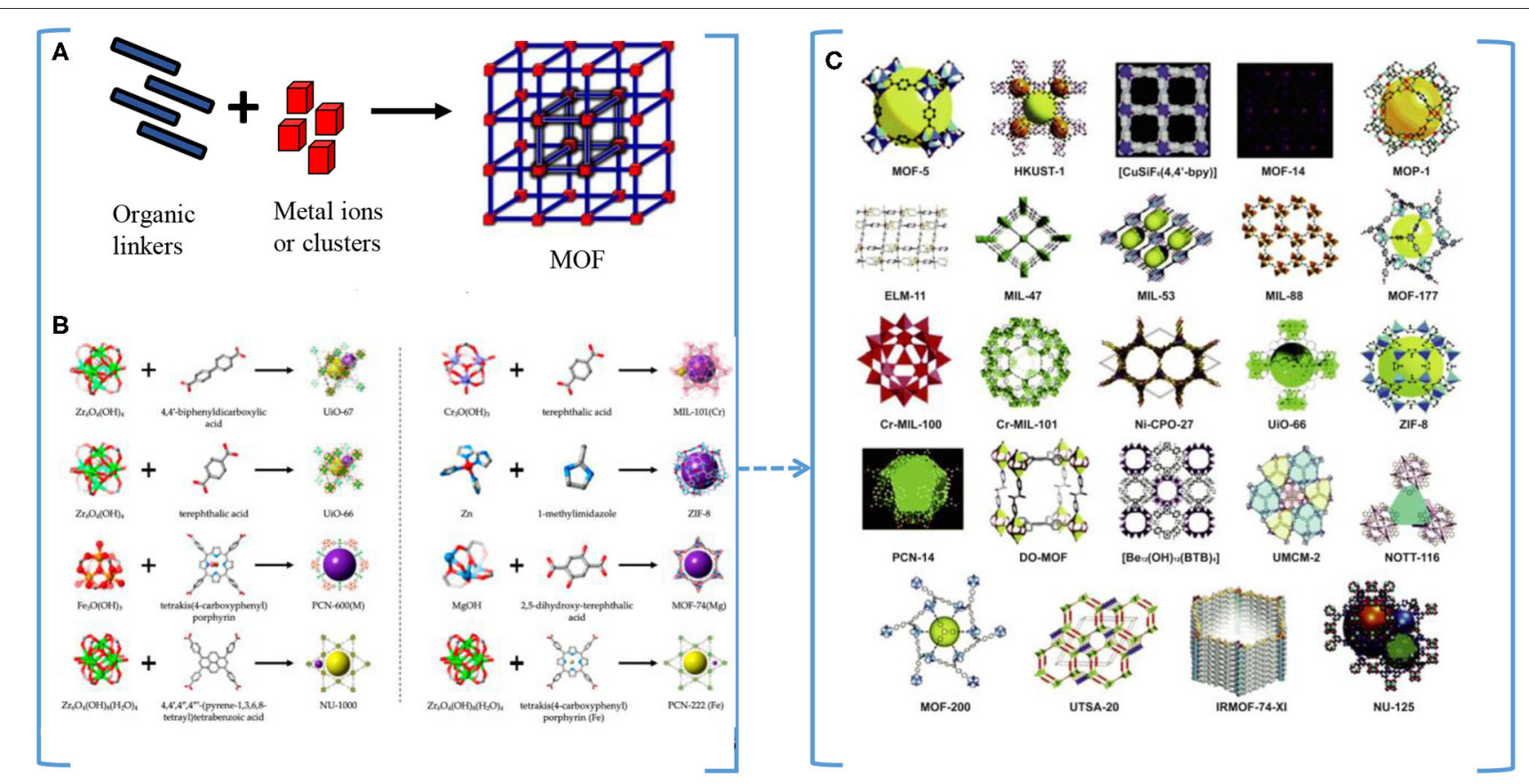

FIGURE 4 | (A) Metallic organic framework (MOF) basic structure. (B) Examples of different MOFs structures with their corresponding metallic clusters and organic linkers (Howarth et al., 2017), with permission from the American Chemical Society. (C) Examples of common MOFs structures (Qiu et al., 2014), with permission from the Royal Society of Chemistry.

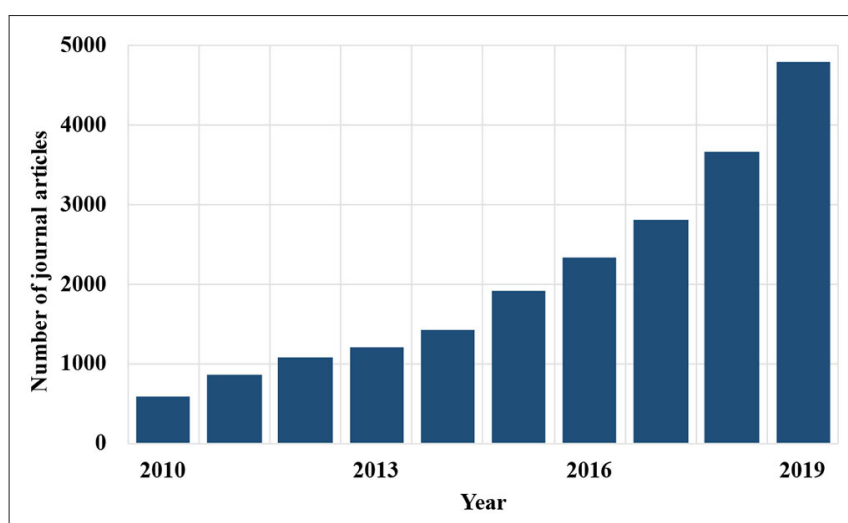

FIGURE 5 | Chronological literature researches on MOFs, keywords, metal organic frameworks, and MOFs (retrieved from Scopus).

hours to weeks to lead to the production of crystals that can undergo to single crystal X-ray diffraction analysis and is not applicable when using starting materials that are unstable at high temperatures (Stock and Biswas, 2012). For some MOFs, crystallization requires a short time, thus they are obtained at room temperature by the direct precipitation method, which consists in just mixing the starting materials. Other methods include microwave-assisted, electrochemical, mechanochemical, and sonochemical synthesis; these approaches differ in how energy is introduced in the synthetic system and result in different reaction time, yields, particle size, and morphology.
Application of MOFs is a multidirection research field. Several applications include $\mathrm{H}_{2} / \mathrm{CH}_{4}$ storage (Yang et al., 2012; Akhbari and Morsali, 2013), $\mathrm{CO}_{2}$ capture (Ding et al., 2016), gas separations (Zhao et al., 2013), and catalysis (Doonan and Sumby, 2017). Very promising results have been obtained by studying the applications of MOFs in adsorption and photocatalytic degradation processes for the abatement of inorganic and organic contaminants. The review pays attention just on these two applications to organic ECs.

\section{MOFS AS ADSORBENTS}

MOFs are good materials for a future application in the field of EC removal from wastewater through adsorption due to the high porosity and the specific adsorbate/adsorbent interactions (Dias and Petit, 2015). ZIF-8 belongs to the zeolitic imidazolate frameworks (ZIFs), a promising class of MOFs for water-phase adsorption application with good chemical and thermal stability and similar pore topologies to zeolites. ZIF- 8 was used by Khan et al. (2015) for phthalic acid adsorption in water. The authors compared the adsorption capacity of ZIF8 with activated carbon (AC), UiO-66, and $\mathrm{NH}_{2}-\mathrm{UiO}-66$, for $24 \mathrm{~h}$ at room temperature. Their results for the sorption capacity $\mathrm{q}_{t}(\mathrm{mg} / \mathrm{g})$ are reported in Table 1.

The highest sorption capacity was found in ZIF-8, and this was explained by a good interaction between the positively charged surface of ZIF-8 and the phthalic acid anions. ZIF-8 proved stable after washing with methanol. 
TABLE 1 | Phthalic acid adsorption tests.

\begin{tabular}{lc}
\hline Adsorbent & $\mathbf{q}_{\mathbf{t}} \mathbf{( \mathbf { m g } / \mathbf { g } )}$ \\
\hline $\mathrm{ZIF}-8$ & $\approx 530$ \\
$\mathrm{AC}$ & $\approx 220$ \\
$\mathrm{NH}_{2}-\mathrm{UiO}-66$ & $\approx 175$ \\
$\mathrm{UiO}-66$ & $\approx 140$ \\
\hline
\end{tabular}

TABLE 2 | Dye removal using Materials Institut Lavoisiers (MILs).

\begin{tabular}{lccc}
\hline Adsorbent & \multicolumn{3}{c}{ Dye removal (\%) } \\
\cline { 2 - 4 } & Basic blue 41 & Methylene blue & Basic red 46 \\
\hline MIL-125(Ti) & 41 & 39 & 45 \\
NH 2 -MIL-125(Ti) & 93 & 97 & 99 \\
MIL-X1 & 45 & 43 & 50 \\
MIL-X2 & 80 & 89 & 75 \\
MIL-X3 & 86 & 91 & 79 \\
\hline
\end{tabular}

Oveisi et al. (2018) synthesized five MOFs named Materials Institut Lavoisiers (MILs) using tetraisopropyl orthotitanate as a metal source and 1,4-benzenedicarboxylate (BDC) and 2-amino1,4-benzenedicarboxylate $\left(\mathrm{NH}_{2}-\mathrm{BDC}\right)$ as organic linkers. The five nanomaterials were MIL-125(Ti), $\mathrm{NH}_{2}$-MIL-125(Ti), MILX1 (BDC/NH2 $-\mathrm{BDC}$ molar ratio: 75/25), MIL-X2 (BDC/ $\mathrm{NH}_{2}-$ BDC molar ratio: 50/50), and MIL-X3 (BDC/ $\mathrm{NH}_{2}-\mathrm{BDC}$ molar ratio: 25/75). Adsorption of three dyes was tested: basic red 46, basic blue 41, and methylene blue. Table 2 shows the results.

The better performances of the amino-functionalized material were attributed to the fact that it has the highest electron density and zeta potential among the tested materials. The authors also studied the adsorbent loading effect, the concentration of each dye, the $\mathrm{pH}$ of the solution, and the contact time on the adsorption process. The following results were obtained: (i) the adsorption efficiency increased with the sorbent loading, since a higher amount of active sites was available, while it decreased with increasing concentration of the dyes due to the saturation of the active sites and/or dye aggregation; (ii) the equilibrium time for the process was $30 \mathrm{~min}$; (iii) no effect was observed as a consequence of $\mathrm{pH}$ variation. This was explained by assuming that the dye adsorption was mainly based on $\pi-\pi$ interactions between adsorbate and adsorbent, which are not influenced by $\mathrm{pH}$ variation.

Andrew Lin and Hsieh (2015) used HKUST-1, a copper-based MOF, for the adsorption of p-nitrophenol (PNP) in water, finding an adsorption capacity of $\approx 400 \mathrm{mg} / \mathrm{g}$. This high value was attributed to the affinity of the metal site of HKUST-1with the $\mathrm{NO}_{2}$ group of PNP as well as $\pi-\pi$ interactions between adsorbate and adsorbent. At $20^{\circ} \mathrm{C}$, adsorption reached equilibrium after $60 \mathrm{~min}$, while at $60^{\circ} \mathrm{C}$, the adsorption capacity was higher, and the equilibrium time decreased to $30 \mathrm{~min}$.

A common drawback of MOFs is a poor processability and low thermal and chemical stability (Li and Huo, 2015). To overcome these drawbacks, a combination of MOFs with
TABLE 3 | Aniline adsorption tests.

\begin{tabular}{lc}
\hline Adsorbent & $\mathbf{q}_{\mathbf{t}} \mathbf{( \mathbf { m g } / \mathbf { g } )}$ \\
\hline $7 \% \mathrm{SiO}_{2} @ \mathrm{MIL}-68$ & 531.9 \\
$\mathrm{SiO}_{2}$ & $\approx 50$ \\
$\mathrm{MIL}-68$ & 402.0 \\
$\mathrm{SiO}_{2} / \mathrm{MIL}-68$ mixture & $\approx 400$ \\
\hline
\end{tabular}

other functional materials has been proposed (Han et al., 2016), in order to realize composites characterized by good performances, improved morphology, and better stability and mechanical properties.

Han et al. (2016) prepared a hybrid material by combining MIL-68, an aluminum-based MOF, with $\mathrm{SiO}_{2}$. They found that the incorporation of $\mathrm{SiO}_{2}$ in MIL-68 results in smaller particle size of MIL-68(Al). The sorption capacity of the $7 \% \mathrm{SiO}_{2} @ \mathrm{MIL}-68(\mathrm{Al})$ composites for aqueous solution of aniline was investigated and compared with that of the individual $\mathrm{SiO}_{2}$ and MIL-68 and a physical mixture of both. The results are listed in Table 3.

The 7\% $\mathrm{SiO}_{2} @$ MIL-68 composite showed a high adsorption capacity and fast adsorption dynamics (the equilibrium was reached in $40 \mathrm{~s}$ ). These results were attributed to the pore size decrease due to incorporation of $\mathrm{SiO}_{2}$ and the likely hydrogen bond interaction between $-\mathrm{NH}_{2}$ of aniline and the bridging $\mu_{2}-\mathrm{O}$ in the adsorbent, as well as the $\pi-\pi$ interaction between the adsorbent and the benzene rings. Moreover, incorporation of $\mathrm{SiO}_{2}$ in the MIL-68 framework reduces its particle size and increases the surface area of the material. The $7 \% \mathrm{SiO}_{2} @ \mathrm{MIL}-$ 68 also showed good reusability. After the fourth reuse, with a regeneration procedure consisting in washing the adsorbent with ethanol then drying it under vacuum at $373 \mathrm{~K}$, the adsorption capacity underwent only a slight reduction.

Jabbari et al. (2016) synthesized hybrid nanocomposites based on Cu-BTC (BTC: benzene tricarboxylate) MOF, carbon nanotubes (CNTs), graphene oxide (GO), and $\mathrm{Fe}_{3} \mathrm{O}_{4}$ magnetic nanoparticles (MNPs) and tested the adsorption capacity of these materials over methylene blue (MB) in 50 and 100 ppm aqueous solutions of the pollutant. Their results are reported in Table 4, where CuG12, CuG11, CuG21, and CuG51 indicate composites with MOF:GO ratios of 1:2, 1:1, 2:1, and 5:1, respectively; $\mathrm{FCuG}$ refers to the $\mathrm{Fe}_{3} \mathrm{O}_{4} / \mathrm{Cu}$-BTC@GO nanocomposite; $\mathrm{CuC12}$, $\mathrm{CuC11}, \mathrm{CuC} 21$, and $\mathrm{CuC5} 1$ indicate composites with MOF/CNT ratio $1: 2,1: 1,2: 1$, and 5:1, respectively; $\mathrm{FCuC}$ indicates a hybrid nanocomposite of $\mathrm{Fe}_{3} \mathrm{O}_{4} / \mathrm{Cu}-\mathrm{BTC} @ \mathrm{CNT}$.

Results show that the nanocomposites performed better than the parent materials, due to the synergistic effect of the composite constituents, nano-size of the Cu-BTC MOF, well separation of the MOF, inhibition of distortion and bundling in GO and CNT, and increasing in pore volume. Unsaturated bonds and the carboxylate group negative charge favors the $\pi-\pi$ and electrostatic interactions between the adsorbent and adsorbate. The best adsorption performances were shown by $\mathrm{CuC} 21$; the measured dye adsorption of the non-magnetic $\mathrm{CuC}$ hybrid nanocomposites is slightly higher than the one obtained with 
TABLE 4 | Methylene blue (MB) adsorption capacities, $Q_{e}$ in $\mathrm{mg} / \mathrm{g}$, of various hybrid nanocomposites.

\begin{tabular}{lll}
\hline Adsorbent & \multicolumn{2}{c}{$\mathbf{Q}_{\mathbf{e}} \mathbf{( \mathbf { m g } / \mathbf { g } )}$} \\
\cline { 2 - 3 } & $\mathbf{C}_{\mathbf{M B}} \mathbf{:} \mathbf{5 0} \mathbf{~ p p m}$ & $\mathbf{C}_{\mathbf{M B}} \mathbf{1} \mathbf{1 0 0} \mathbf{~ p p m}$ \\
\hline $\mathrm{Fe}_{3} \mathrm{O}_{4}$ MNPs & 62 & 80 \\
Graphene oxide (GO) & 71 & 94 \\
F-CNT & 110 & 125 \\
Cu-BTC MOF & 46 & 67 \\
CuG12 & 48 & 128 \\
CuG11 & 88 & 96 \\
CuG21 & 32 & 152 \\
CuG51 & 28 & 40 \\
FCuG & 79 & 136 \\
CuC12 & 90 & 108 \\
CuC11 & 78 & 160 \\
CuC21 & 130 & 172 \\
CuC51 & 136 & 132 \\
FCuC & 112 & 152 \\
\end{tabular}

TABLE 5 | Bisphenol A (BPA) adsorption capacities of various hybrid nanocomposites.

\begin{tabular}{lc}
\hline Adsorbent & $\mathbf{q e}_{\mathrm{e}} \mathbf{( \mathbf { m g } / \mathbf { g } )}$ \\
\hline GO & 99.7 \\
F-CNT & 82.9 \\
Cu-BDC & 60.2 \\
Cu1GrO1 & 161.8 \\
Cu1GrO3 & 182.2 \\
Cu3GrO1 & 148.9 \\
Cu1CNT1 & 146.7 \\
Cu1CNT3 & 164.1 \\
Cu3CNT1 & 129.7 \\
\hline
\end{tabular}

the magnetic hybrid nanocomposite of FCuC. This could be explained by the filling of the pores formed between the MOF and the substrate by magnetic nanoparticles and/or disruption of the connection between the parent materials after loading of MNPs.

Recently, Ahsan et al. (2019) prepared a similar set of MOF-GO and MOF-CNT nanocomposites, this time using $\mathrm{Cu}-$ BDC (BDC: benzene dicarboxylate) for adsorption of bisphenol A (BPA) in $100 \mathrm{ppm}$ aqueous solutions. Table 5 reports their results.

The data show that the newly formed CuMOF-based hybrid nanocomposites have higher adsorption capacities for the BPA removal. This is attributed to the synergy coming into play when the parent materials are combined. Moreover, the functionalized graphene layer (i) suppresses aggregation, benefits dispersion, and increases the formation of small pores, (ii) reduces interMOF voids and preserves MOF formation and growth, and (iii) prevents the distortions and buckling/bundling of the GrO and CNTs. Another effect, which could favor BPA adsorption is the formation of new pores at the interface of $\mathrm{Cu}-\mathrm{BDC}$ with
$\mathrm{MOF} / \mathrm{CNT}$ and $\mathrm{Cu}-\mathrm{BDC}$ with $\mathrm{MOF} / \mathrm{GrO}$, due to the binding of the $\mathrm{Cu}-\mathrm{BDC} \mathrm{MOF}$ to the graphene layers in CNTs and GrO.

The wide literature has highlighted a number of different selective adsorption mechanisms in the abatement of organic compounds by MOFs:

- Electrostatic: this type of interaction has been the most frequently observed. The surface charge of the MOF depends on the $\mathrm{pH}$ of the solution; the charged MOF undergoes electrostatic interaction with an oppositely charged contaminant.

- Hydrogen bonding: MOFs can be functionalized with $\mathrm{NH}_{2}$, $-\mathrm{OH},-\mathrm{COOH}$, and $-\mathrm{SO}_{3} \mathrm{H}$ groups, to enable adsorptive removal applications via hydrogen bonding (Hasan et al., 2013). The different groups induce different strengths of the hydrogen bonding.

- Acid-base: Ahmed and Jhung (2017) reported the effects of the functionalization of the MOF MIL-101-Cr with either acidic or basic groups on naproxen adsorption. Results showed that the basic functionalized MOF was a better adsorbent than the acidic functionalized and the neutral MIL-101. This is due to the interaction between the modified MOFs' with $-\mathrm{NH}_{2}$ groups with the sorbates $-\mathrm{COOH}$ groups.

- $\pi-\pi$ interactions/stacking: Qin et al. (2015) reported that the amount of bisphenol A adsorbed over MIL-101-Cr was 1.84 times higher than on activated carbon, suggesting the existence of $\pi-\pi$ interactions between the adsorbent and benzene rings.

- Pore/size-selective adsorption: one of the most interesting features of MOFs is the related pore size tunability, which enables selective adsorption of appropriately sized sorbates. As shown by Huang et al. (2012), it is possible to favor mesopore formation during MOF synthesis in order to enhance methylene blue (MB) adsorption.

- Hydrophobic interactions: higher hydrophobicity in MOFs favors their adsorption of non-polar, water-insoluble molecules, as reported by Sann et al. (2018) who observed high adsorption of oil over the highly hydrophobic MOF ZIF-8 (zinc-methylimidazolate framework-8).

Table 6 reports up-to-date studies and the corresponding adsorption capacity of different types of MOFs in ECs remediation.

\section{METAL ORGANIC FRAMEWORKS AS PHOTOCATALYSTS}

Photodegradation is theoretically a better method than adsorption for wastewater treatment, mainly because it causes a complete elimination of the pollutant instead of its simple phase transfer, so no further treatment is required. The presence of organic linkers in MOFs allows them to have a relatively wide absorption spectrum permitting the generation of a charge-separated state, which decays in the microseconds, thus permitting photocatalytic applications (Hariganesh et al., 2020; Wang C. et al., 2020).

Alvaro et al. (2007) investigated the behavior of MOF-5, containing clusters of $\mathrm{ZnO}$, as a semiconductor. They found that 
TABLE 6 | Comparison of the adsorption capacity of different types of metal organic frameworks (MOFs) for emerging contaminant (EC) remediation.

\begin{tabular}{|c|c|c|c|c|}
\hline Functionalized MOF & $\begin{array}{l}\text { Surface area } \\
\qquad\left(\mathrm{m}^{2} / \mathrm{g}\right)\end{array}$ & EC remediated & $\begin{array}{l}\text { Adsorption capacity } \\
\qquad(\mathrm{mg} / \mathrm{g})\end{array}$ & References \\
\hline $\begin{array}{l}\mathrm{MIL}-53(\mathrm{Fe}) \\
\mathrm{NH}_{2}-\mathrm{MlL}-53(\mathrm{Fe}) \\
\mathrm{NO}_{2}-\mathrm{MIL}-53(\mathrm{Fe}) \\
\mathrm{Br}-\mathrm{MIL}-53(\mathrm{Fe})\end{array}$ & $\begin{array}{l}52.12 \\
65.64 \\
30.01 \\
39.75\end{array}$ & Tetracycline antibiotics & $\begin{array}{l}247.70 \\
271.90 \\
272.60 \\
309.60\end{array}$ & Yu et al., 2019 \\
\hline Al-MOF-Fe ${ }_{3} \mathrm{O}_{4} @ \mathrm{P} 4$ V P & 123.67 & Naproxen & 31.67 & Li Y. et al., 2020 \\
\hline $\mathrm{SCNU}-\mathrm{Z}_{2}$ & 960.00 & $\begin{array}{l}\text { Methylene blue } \\
\text { Crystal violet } \\
\text { Rhodamine B }\end{array}$ & $\begin{array}{l}455.60 \\
847.40 \\
751.80\end{array}$ & Deng et al., 2019 \\
\hline $\mathrm{Ti}_{3} \mathrm{C}_{2} \mathrm{~T}_{x} \mathrm{MXene}$ and Al-MOF & $\begin{array}{c}9.00 \text { and } \\
630.00\end{array}$ & $\begin{array}{l}\text { Methylene blue } \\
\text { Acid blue } 80\end{array}$ & $\begin{array}{l}\sim 140 \\
\sim 200\end{array}$ & Jun et al., 2020 \\
\hline $\begin{array}{l}\text { Ni-BDC MOF } \\
\text { Ni-BDC MOF@GO } \\
\text { Ni-MOF@CNT }\end{array}$ & - & Methylene blue & $\begin{array}{c}73.48 \\
222.80 \\
181.96\end{array}$ & Ahsan et al., 2020 \\
\hline ZIF-8-chitosan composite beads & 15.30 & Tetracycline & 495.04 & Zhao et al., 2020 \\
\hline ZIF-8@CS/PVA-ENF(2) & - & Malachite green & $1,000.00$ & Mahmoodi et al., 2020 \\
\hline Zr-MOF(bpy) & $2,141.88$ & Rhodamine B & 918.90 & Cui et al., 2019 \\
\hline BMDC-12h & $1,449.00$ & $\begin{array}{l}\text { Atenolol } \\
\text { Clofibric acid }\end{array}$ & $\begin{array}{l}552.00 \\
540.00\end{array}$ & Bhadra and Jhung, 2018 \\
\hline
\end{tabular}

TABLE 7 | Photodegradation of phenol with various catalysts.

\begin{tabular}{lcc}
\hline Catalyst & $\begin{array}{c}\text { Molephenol } \\
\text { degraded/g } \\
\text { catalyst }\end{array}$ & $\begin{array}{c}\text { Mole phenol } \\
\text { degraded/catalyst } \\
\text { metal atom }\end{array}$ \\
\hline MOF-5 & 0.0045 & 1.30 \\
P25 & 0.0125 & 0.92 \\
ZnO & 0.0120 & 0.90 \\
\hline
\end{tabular}

this material is stable to light exposure, has an absorption onset at $450 \mathrm{~nm}$ and a $3.4 \mathrm{eV}$ band gap. Irradiation with $\lambda<450 \mathrm{~nm}$ gives rise to an electron-hole couple lasting for microseconds, thus permitting application in photocatalytic processes. The activity of MOF-5 was tested in the photodegradation reaction of phenol and compared with Degussa P25 ( $\mathrm{TiO}_{2}$ nanoparticles) and another semiconductor, $\mathrm{ZnO}$. The degradation of MOF5 generates $\mathrm{ZnO}$, and this could be responsible for the photocatalytic activity.

As shown in Table 7, MOF-5 has a high photocatalytic activity, which is not caused by $\mathrm{ZnO}$ clusters eventually formed during the test, due to the higher phenol conversion per metal atom when compared to $\mathrm{ZnO}$.

Effect on photocatalytic activity of MOF modification, especially by inclusion of inorganic semiconductors, was also studied by Binh et al. (2015). The authors prepared a $\mathrm{Cu}_{3} \mathrm{BTC}_{2}$ (BTC = benzene-1,3,5-tricarboxylate) MOF with a specific surface area of $1,350 \mathrm{~m}^{2} / \mathrm{g}$, which was then modified by including $\mathrm{TiO}_{2}$ in its framework and converted to $\mathrm{TiO}_{2} @ \mathrm{Cu}_{3} \mathrm{BTC}_{2}$. The catalytic activity of the novel material was tested in the photodegradation of methylene blue $(\mathrm{MB})$ and compared to that with the commercial $\mathrm{TiO}_{2}$ photocatalyst Degussa P25. The photocatalytic experiments were performed using $50 \mathrm{ml}$ of
TABLE 8 | Methylene Blue (MB) photodegradation using $\mathrm{TiO}_{2} @ \mathrm{Cu}_{3} \mathrm{BTC}_{2}$ and $\mathrm{TiO}_{2}$.

\begin{tabular}{lcccc}
\hline Catalyst & \multicolumn{4}{c}{ MB C/C } \\
\cline { 2 - 5 } & t: $\mathbf{2}$ min & t: $\mathbf{6}$ min & t: $\mathbf{1 0}$ min & t: $\mathbf{3 0}$ min \\
\hline $\mathrm{TiO}_{2} @ \mathrm{Cu}_{3} \mathrm{BTC}_{2}$ & 0.3 & 0.15 & 0.10 & 0.09 \\
$\mathrm{TiO}_{2}$ & 0.9 & 0.8 & 0.7 & 0.2 \\
\hline
\end{tabular}

aqueous methylene blue solution $\left(2 \times 10^{-5} \mathrm{M}\right)$ in which the photocatalyst was dispersed $(3 \mathrm{mg} / \mathrm{ml})$. The resulting mixture was irradiated under UV-Vis lamps, at different irradiation times, from 2 to $30 \mathrm{~min}$. Table 8 shows the experimental data.

The data show that $\mathrm{TiO}_{2} @ \mathrm{Cu}_{3} \mathrm{BTC}_{2}$ is a promising photodegradation catalyst since it performs faster than Degussa P25 in the photocatalytic degradation of Methylene Blue. This has been attributed to spectral sensitization of the colored $\mathrm{Cu}-\mathrm{MOF}$ for $\mathrm{TiO}_{2}$ in the visible region, to the large contact area of the catalyst, to high porosity, and to $\mathrm{Cu}_{3} \mathrm{BTC}_{2}$ acting as template for the formation of fine nano $\mathrm{TiO}_{2}$ with an increase in surface area.

In an effort to increase the photocatalytic activity of MOFs toward solar light, Gómez-Avilés et al. (2019) synthesized mixed $\mathrm{Ti}-\mathrm{Zr}$ MOFs by substituting partially $\mathrm{Ti}$ by $\mathrm{Zr}$ atoms in the framework of $\mathrm{NH}_{2}$-MIL-125(Ti) $\mathrm{MOF}$ and tested them in acetaminophen (ACE) photodegradation experiments under solar-simulated radiation. The synthesized materials had different Ti:Zr molar percentages and were named TiZr15, TiZr30, TiZr60, and TiZr80, the number standing for the $\mathrm{Zr}$ molar percentage. Before the photocatalytic runs, adsorption and solar irradiation tests were performed, showing that adsorption ranged between 0.6 and $2 \%$ and that the ACE concentration was 
TABLE 9 | Acetaminophen (ACE) photodegradation using different catalysts.

\begin{tabular}{|c|c|c|c|c|c|c|c|c|c|}
\hline \multirow[t]{2}{*}{ Catalyst } & \multicolumn{9}{|c|}{ ACE $\mathrm{C} / \mathrm{C}_{0}$} \\
\hline & $\mathrm{t}: 15 \mathrm{~min}$ & $\mathrm{t}: \mathbf{3 0} \mathrm{min}$ & $\mathrm{t}: 45 \mathrm{~min}$ & $\mathrm{t}: 60 \mathrm{~min}$ & $\mathrm{t}: 90 \mathrm{~min}$ & $\mathrm{t}: 120 \mathrm{~min}$ & $\mathrm{t}: 180 \mathrm{~min}$ & $\mathrm{t}: 240 \mathrm{~min}$ & $\mathrm{t}: 360 \mathrm{~min}$ \\
\hline $\mathrm{NH}_{2}-\mathrm{MIL}-125(\mathrm{Ti})$ & 0.93 & 0.86 & 0.73 & 0.57 & 0.26 & 0.09 & 0 & 0 & 0 \\
\hline TiZr15 & 0.82 & 0.66 & 0.41 & 0.23 & 0.03 & 0 & 0 & 0 & 0 \\
\hline TiZr30 & 0.9 & 0.72 & 0.6 & 0.45 & 0.23 & 0.02 & 0 & 0 & 0 \\
\hline TiZr60 & 0.97 & 0.93 & 0.9 & 0.88 & 0.82 & 0.76 & 0.7 & 0.64 & 0.53 \\
\hline TiZr80 & 0.97 & 0.93 & 0.9 & 0.88 & 0.82 & 0.76 & 0.69 & 0.61 & 0.51 \\
\hline
\end{tabular}

unchanged after $6 \mathrm{~h}$ of solar irradiation in the absence of catalyst. The photocatalytic tests were performed at $20^{\circ} \mathrm{C}$ with $150 \mathrm{ml}$ of solution containing $5 \mathrm{mg} / \mathrm{L}$ of ACE at time zero, in which a catalyst amount of $250 \mathrm{mg} / \mathrm{L}$ was added, at an initial $\mathrm{pH}$ of 6.9 , with an intensity of irradiation equal to $600 \mathrm{~W} / \mathrm{m}^{2}$. Table 9 shows the results.

The non-crystalline samples with the highest $\mathrm{Zr}$ percentage (TiZr60 and TiZr80) yielded lower acetaminophen conversion. TiZr15 and TiZr30, characterized by the lower Zr amounts, caused complete ACE photodegradation in $<3 \mathrm{~h}$ of irradiation. The high performance of TiZr15, which allowed complete ACE conversion within $90 \mathrm{~min}$ was explained by the high porosity and lower band gap value resulting from the partial substitution of $\mathrm{Ti}^{4+}$ by $\mathrm{Zr}^{4+}$ in the structure of the MOF. The incorporation of $\mathrm{Zr}$ ions, which are able to act as charge trappers, increases the charge carrier lifetimes and reduces the recombination processes, resulting in an increase in photoactivity.

The incorporation of the $-\mathrm{NH}_{2}$ group to the organic linker also affects the photoactivity of these materials. It causes the formation of a red shifted band at the valance bond (VB) of the MOF, reducing the band gap value to $2.7 \mathrm{eV}$, thus enabling photoexcitation as a result of irradiation with photons with $\lambda$ $=460 \mathrm{~nm}$ and lower. Moreover, the amine group increases the charge transfer between metal and organic linker and inhibits electron-hole recombination. It is also notable that no aromatic intermediates were detected using HPLC (probably due to low initial ACE concentration and/or fast conversion to other organics). TiZr15, the most active photocatalyst, was active after three successive runs.

Another recent work focused on the synthesis of MOFbased photocatalysts activated by visible light. He et al. (2019) prepared a magnetic (M-) MIL-101(Fe)/ $/ \mathrm{TiO}_{2}$ composite for the photodegradation of tetracycline under solar light irradiation. The catalytic efficiency of M-MIL-101(Fe)/TiO (magnetic) $^{2}$ and $\mathrm{MIL}-101(\mathrm{Fe}) / \mathrm{TiO}_{2}$ (non-magnetic) for tetracycline (TC) degradation was investigated under visible light: after $3 \mathrm{~h}$ of TC conversion, 91.24 and $84.85 \%$, respectively. This difference was attributed to the lower recombination rate observed for the magnetic material. Process optimization tests showed that using $1 \mathrm{~g} / \mathrm{L}$ of catalyst in a $20-\mathrm{mg} / \mathrm{L}$ of aqueous solution of $\mathrm{TC}$ at initial $\mathrm{pH}$ of 7 at $25^{\circ} \mathrm{C}$ under direct solar irradiation, $92.76 \%$ TC conversion was obtained in $10 \mathrm{~min}$. The material was magnetically separated from the solution and reused, showing similar performances after five catalytic cycles. It is important to point out that this high degradation rate was obtained under solar irradiation, while artificial visible light irradiation yielded poorer results, suggesting that UV photons in solar light have an important role in the photoexcitation process.

\section{CONCLUSIONS, CHALLENGES, AND FUTURE PERSPECTIVE}

Up to now, various applications of MOFs are under investigation, as they exhibit high versatility, low production costs, and high efficiency. Particularly, MOFs show promising incorporation in wastewater treatment technologies on an industrial scale. The tunability of their structural and electronic features gives the possibility to prepare materials, which can be both good adsorbents and efficient photodegradation catalysts. However, the development and the sophistication of new synthetic MOFs face challenges that stem from the chemistry of these materials and their future applications. In addition, the prospect of wide-scale implementation of MOFs in wastewater treatment is promising but needs further investigation, mainly considering scaling up application to study their performances in real conditions. In this review, we have summarized the fundamentals of adsorption and photodegradation as common applications in MOFs for EC remediation in wastewater. Moreover, focus has been given to cutting edge researches pertaining to these applications. MOF pore size can be appropriately tuned to accommodate a specific pollutant. MOFs can also be functionalized to enhance electrostatic, acid-base, $\pi-\pi$ interactions, or hydrogen bonding. They can be combined with metals, inorganic semiconductors, or organic linkers to enhance their photoexcitation rate and reduce electronhole recombination in order to obtain composites with high photocatalytic efficiencies. In summary, MOFs are one of the hottest topics of research today. Their phenomenal and promising features in EC remediation make MOFs very tempting materials for researchers to further explore and investigate in different potential directions.

\section{AUTHOR CONTRIBUTIONS}

VR and FB wrote the original draft of the manuscript with support from MI and MD. The main conceptual ideas were drawn from the interactions between $\mathrm{VR}$ and $\mathrm{MD}$, while the 
funds were obtained by the synergistic effect of the cooperation between O-SJ and MD. The development of the artworks, the data elaboration, and the formal analysis were conducted by VR, $\mathrm{MH}$, and FB. The final draft was corrected by $\mathrm{MH}, \mathrm{MI}$, and MD. All authors contributed to the article and approved the submitted version.

\section{REFERENCES}

Ahmed, I., and Jhung, S. H. (2017). Applications of metal-organic frameworks in adsorption/separation processes via hydrogen bonding interactions. Chem. Eng. J. 310, 197-215. doi: 10.1016/j.cej.2016.10.115

Ahsan, M. A., Jabbari, V., Imam, M. A., Castro, E., Kim, H., Curry, M. L., et al. (2020). Nanoscale nickel metal organic framework decorated over graphene oxide and carbon nanotubes for water remediation. Sci. Total Environ. 698:134214. doi: 10.1016/j.scitotenv.2019.134214

Ahsan, M. A., Jabbari, V., Islam, M. T., Turley, R. S., Dominguez, N., Kim, H., et al. (2019). Sustainable synthesis and remarkable adsorption capacity of $\mathrm{MOF} /$ graphene oxide and MOF/CNT based hybrid nanocomposites for the removal of Bisphenol A from water. Sci. Total Environ. 673, 306-317. doi: 10.1016/j.scitotenv.2019.03.219

Akhbari, K., and Morsali, A. (2013). Modulating methane storage in anionic nano-porous MOF materials via post-synthetic cation exchange process. Dalton Trans. 42, 4786-4789. doi: 10.1039/c3dt32846e

Akpinar, I., and Yazaydin, A. O. (2017). Rapid and efficient removal of carbamazepine from water by UiO-67. Ind. Eng. Chem. Res. 56, 15122-15130. doi: 10.1021/acs.iecr.7b03208

Alnaizy, R., and Akgerman, A. (2000). Advanced oxidation of phenolic compounds. Adv. Environ. Res. 4, 233-244. doi: 10.1016/S1093-0191(00)00024-1

Alvaro, M., Carbonell, E., Ferrer, B., Llabrés i Xamena, F. X., and Garcia, H. (2007). Semiconductor behavior of a Metal-Organic Framework (MOF). Chemistry 13, 5106-5112. doi: 10.1002/chem.200601003

Ameta, S. C., and Ameta, R. (2018). Advanced Oxidation Processes for Waste Water Treatment. Cambridge: Academic Press.

Andrew Lin, K. Y., and Hsieh, Y. T. (2015). Copper-based metal organic framework (MOF), HKUST-1, as an efficient adsorbent to remove p-nitrophenol from water. J. Taiwan Inst. Chem. Eng. 50, 223-228. doi: 10.1016/j.jtice.2014.12.008

Araña, J., Martinez Nieto, J. L., Herrera Melián, J. A., Doña Rodriguez, J. M., González Diaz, O., Pérez Peña, J., et al. (2004). Photocatalytic degradation of formaldehyde containing wastewater from veterinarian laboratories. Chemosphere 55, 893-904. doi: 10.1016/j.chemosphere.2003.11.060

Bedia, J., Muelas-Ramos, V., Peñas-Garzón, M., Gómez-Avilés, A., Rodríguez, J. J., and Belver, C. (2019). A review on the synthesis and characterization of metal organic frameworks for photocatalytic water purification. Catalysts. 9:52. doi: $10.3390 /$ catal9010052

Bhadra, B. N., and Jhung, S. H. (2018). Adsorptive removal of wide range of pharmaceuticals and personal care products from water using bioMOF-1 derived porous carbon. Micropor. Mesopor. Mater. 270, 102-108. doi: 10.1016/j.micromeso.2018.05.005

Binh, N. T., Thu, P. T., Le, N. T. H., Tien, D. M., Khuyen, H. T., Giang, L. T. K., et al. (2015). Study on preparation and properties of a novel photo-catalytic material based on copper-centred metal-organic frameworks (Cu-MOF) and titanium dioxide. Int. J. Nanotech. 12, 447-455. doi: 10.1504/IJNT.2015.067902

Butova, V. V., Soldatov, M. A., Guda, A. A., Lomachenko, K. A., and Lamberti, C. (2016). Metal-organic frameworks: structure, properties, methods of synthesis and characterization. Russian Chem. Rev. 85, 280 -307. doi: 10.1070/RCR4554

Cheng, P., Wang, C., Kaneti, Y. V., Eguchi, M., Lin, J., Yamauchi, Y., et al. (2020). Practical MOF nanoarchitectonics: new strategies for enhancing the processability of MOFs for practical applications. Langmuir 36, 4231-4249. doi: 10.1021/acs.langmuir.0c00236

Cheremisinoff, N. P. (2007). Handbook of Water and Wastewater Treatment Technologies. Waltham: Butterworth-Heinemann.

\section{FUNDING}

The 12th executive program for scientific and technological cooperation between the Italian Republic and the Republic of Korea for the years 2019-2021 is acknowledged for the financial support.

Chun, H., Yizhong, W., and Hongxiao, T. (2000). Destruction of phenol aqueous solution by photocatalysis or direct photolysis. Chemosphere 41, 1205-1209. doi: 10.1016/S0045-6535(99)00539-1

Crini, G., and Lichtfouse, E. (2019). Advantages and disadvantages of techniques used for wastewater treatment. Environ. Chem. Lett. 17, 145-155. doi: 10.1007/s10311-018-0785-9

Cui, W., Kang, X., Zhang, X., and Cui, X. (2019). Gel-like ZnO/ZrMOF(bpy) nanocomposite for highly efficient adsorption of Rhodamine B dye from aqueous solution. J. Phys. Chem. Solids 134, 165-175. doi: 10.1016/j.jpcs.2019.06.004

Curcó, D., Giménez, J., Addardak, A., Cervera-March, S., and Esplugas, S. (2002). Effects of radiation absorption and catalyst concentration on the photocatalytic degradation of pollutants. Cataly. Today 76, 177-188. doi: 10.1016/S0920-5861(02)00217-1

Daliran, S., Ghazagh-Miri, M., Oveisi, A. R., Khajeh, M., Navalón, S., Âlvaro, M., et al. (2020). A pyridyltriazol functionalized zirconium metal-organic framework for selective and highly efficient adsorption of palladium. ACS Appl. Mater. Interfaces 12, 25221-25232. doi: 10.1021/acsami.0c06672

Deng, S. Q., Miao, Y. L., Tan, Y. L., Fang, H. N., Li, Y. T., Mo, X. J., et al. (2019). An Anionic nanotubular metal-organic framework for high-capacity dye adsorption and dye degradation in darkness. Inorg. Chem. 58, 13979-13987. doi: 10.1021/acs.inorgchem.9b01959

Dhakshinamoorthy, A., Asiri, A. M., and Garcia, H. (2019). 2D metal-organic frameworks as multifunctional materials in heterogeneous catalysis and electro/photocatalysis. Adv. Mater. 31:1900617. doi: 10.1002/adma.201900617

Dhakshinamoorthy, A., Li, Z., and Garcia, H. (2018). Catalysis and photocatalysis by metal organic frameworks. Chem. Soc. Rev. 47, 8134-8172. doi: $10.1039 / \mathrm{C} 8 \mathrm{CS} 00256 \mathrm{H}$

Dias, E. M., and Petit, C. (2015). Towards the use of metal-organic frameworks for water reuse: a review of the recent advances in the field of organic pollutants removal and degradation and the next steps in the field. J. Mater. Chem. A 3, 22484-22506. doi: 10.1039/C5TA05440K

Ding, N., Li, H., Feng, X., Wang, Q., Wang, S., Ma, L., et al. (2016). Partitioning MOF-5 into confined and hydrophobic compartments for carbon capture under humid conditions. J. Am. Chem. Soc. 138, 10100-10103. doi: 10.1021/jacs.6b06051

Doonan, C. J., and Sumby, C. J. (2017). Metal-organic framework catalysis. CrystEngComm. 19, 4044-4048. doi: 10.1039/C7CE90106B

Eddaoudi, M., Li, H., and Yaghi, O. M. (2000). Highly porous and stable metalorganic frameworks: structure design and sorption properties. J. Am. Chem. Soc. 122, 1391-1397. doi: 10.1021/ja9933386

El-Qanni, A. (2017). Development of sustainable nanosorbcats based technology for hydrocarbons and organic pollutants recovery from industrial wastewater. Doctoral thesis. doi: 10.11575/PRISM/28735

Fairbairn, D. J., Elliott, S. M., Kiesling, R. L., Schoenfuss, H. L., Ferrey, M. L., and Westerhoff, B. M. (2018). Contaminants of emerging concern in urban stormwater: spatiotemporal patterns and removal by iron-enhanced sand filters (IESFs). Water Res. 145, 332-345. doi: 10.1016/j.watres.2018.08.020

Farha, O. K., Eryazici, I., Jeong, N. C., Hauser, B. G., Wilmer, C. E., Sarjeant, A. A., et al. (2012). Metal-organic framework materials with ultrahigh surface areas: is the sky the limit? J. Am. Chem. Soc. 134, 15016-15021. doi: 10.1021/ja3055639

Farrusseng, D. (2011). Metal-Organic Frameworks Applications From Catalysis to Gas Storage. Weinheim: Wiley-VCH. doi: 10.1002/9783527635856

Furukawa, H., Cordova, K. E., O'Keeffe, M., and Yaghi, O. M. (2013). The chemistry and applications of metal-organic frameworks. Science 341:1230444. doi: $10.1126 /$ science. 1230444 
Gogate, P. R., and Pandit, A. B. (2004). A review of imperative technologies for wastewater treatment I: oxidation technologies at ambient conditions. Adv. Environ. Res. 8, 501-551. doi: 10.1016/S1093-0191(03)00032-7

Gómez-Avilés, A., Peñas-Garzón, M., Bedia, J., Dionysiou, D. D., Rodríguez, J. J., and Belver, C. (2019). Mixed Ti-Zr metal-organic-frameworks for the photodegradation of acetaminophen under solar irradiation. Appl. Cataly. B 253, 253-262. doi: 10.1016/j.apcatb.2019.04.040

Han, T., Li, C., Guo, X., Huang, H., Liu, D., and Zhong, C. (2016). In-situ synthesis of SiO2@MOF composites for high-efficiency removal of aniline from aqueous solution. Appl. Surf. Sci. 390, 506-512. doi: 10.1016/j.apsusc.2016.08.111

Haque, M. M., and Muneer, M. (2007). Photodegradation of norfloxacin in aqueous suspensions of titanium dioxide. J. Hazard. Mater.. 145, 51-57. doi: 10.1016/j.jhazmat.2006.10.086

Hariganesh, S., Vadivel, S., Maruthamani, D., Kumaravel, M., Paul, B., Balasubramanian, N., et al. (2020). Facile large scale synthesis of $\mathrm{CuCr} 2 \mathrm{O} 4 / \mathrm{CuO}$ nanocomposite using MOF route for photocatalytic degradation of methylene blue and tetracycline under visible light. Appl. Organomet. Chem. 34:e5365. doi: 10.1002/aoc.5365

Hasan, Z., Choi, E. J., and Jhung, S. H. (2013). Adsorption of naproxen and clofibric acid over a metal-organic framework MIL-101 functionalized with acidic and basic groups. Chem. Eng. J. 219, 537-544. doi: 10.1016/j.cej.2013.01.002

Hasan, Z., Jeon, J., and Jhung, S. H. (2012). Adsorptive removal of naproxen and clofibric acid from water using metal-organic frameworks. J. Hazard. Mater. 209-210, 151-157. doi: 10.1016/j.jhazmat.2012.01.005

Hasan, Z., and Jhung, S. H. (2015). Removal of hazardous organics from water using metal-organic frameworks (MOFs): plausible mechanisms for selective adsorptions. J. Hazard. Mater. 283, 329-339. doi: 10.1016/j.jhazmat.2014.09.046

He, L., Dong, Y., Zheng, Y., Jia, Q., Shan, S., and Zhang, Y. (2019). A novel magnetic MIL-101(Fe)/TiO2 composite for photo degradation of tetracycline under solar light. J. Hazard. Mater. 361, 85-94. doi: 10.1016/j.jhazmat.2018.08.079

Herrmann, J. M. (2000). Heterogeneous photocatalysis: fundamentals and applications to the removal of various types of aqueous pollutants. Cataly. Today 53, 115-129. doi: 10.1016/S0920-5861(99)00107-8

Howarth, A. J., Peters, A. W., Vermeulen, N. A., Wang, T. C., Hupp, J. T., and Farha, O. K. (2017). Best practices for the synthesis, activation, and characterization of metal-organic frameworks. Chem. Mater. 29, 26-39. doi: 10.1021/acs.chemmater.6b02626

$\mathrm{Hu}, \mathrm{C}$., Hu, X., Li, R., and Xing, Y. (2020). MOF derived ZnO/C nanocomposite with enhanced adsorption capacity and photocatalytic performance under sunlight. J. Hazard. Mater. 385:121599. doi: 10.1016/j.jhazmat.2019.121599

Huang, X. X., Qiu, L. G., Zhang, W., Yuan, Y. P., Jiang, X., Xie, A. J., et al. (2012). Hierarchically mesostructured MIL-101 metal-organic frameworks: supramolecular template-directed synthesis and accelerated adsorption kinetics for dye removal. CrystEngComm 14, 1613-1617. doi: 10.1039/C1CE06138K

Huber, M. M., Canonica, S., Park, G. Y., and von Gunten, U. (2003). Oxidation of pharmaceuticals during ozonation and advanced oxidation processes. Environ. Sci. Technol. 37, 1016-1024. doi: 10.1021/es025896h

Jabbari, V., Veleta, J. M., Zarei-Chaleshtori, M., Gardea-Torresdey, J., and Villagrán, D. (2016). Green synthesis of magnetic MOF@GO and MOF@CNT hybrid nanocomposites with high adsorption capacity towards organic pollutants. Chem. Eng. J. 304, 774-783. doi: 10.1016/j.cej.2016.06.034

Jun, B. M., Heo, J., Taheri-Qazvini, N., Park, C. M., and Yoon, Y. (2020). Adsorption of selected dyes on Ti3C2Tx MXene and Al-based metal-organic framework. Ceramics Int. 46, 2960-2968. doi: 10.1016/j.ceramint.2019.09.293

Khan, N. A., Jung, B. K., Hasan, Z., and Jhung, S. H. (2015). Adsorption and removal of phthalic acid and diethyl phthalate from water with zeolitic imidazolate and metal-organic frameworks. J. Hazard. Mater. 282, 194-200. doi: 10.1016/j.jhazmat.2014.03.047

Kreno, L. E., Leong, K., Farha, O. K., Allendorf, M., Van Duyne, R. P., and Hupp, J. T. (2012). Metal-organic framework materials as chemical sensors. Chem. Rev. 112, 1105-1125. doi: 10.1021/cr200324t

Kumar, P., Bansal, V., Kim, K. H., and Kwon, E. E. (2018). Metal-organic frameworks (MOFs) as futuristic options for wastewater treatment. J. Ind. Eng. Chem. 62, 130-145. doi: 10.1016/j.jiec.2017.12.051
Li, G., Xia, L., Dong, J., Chen, Y., and Li, Y. (2020). “10 - Metal-organic frameworks," in Solid-Phase Extraction, ed C. F. Poole (Oxford: Elsevier), 285-309. doi: 10.1016/B978-0-12-816906-3.00010-8

Li, S., and Huo, F. (2015). Metal-organic framework composites: from fundamentals to applications. Nanoscale 7, 7482-7501. doi: 10.1039/C5NR00518C

Li, Y., Wang, Y., He, L., Meng, L., Lu, H., and Li, X. (2020). Preparation of poly(4-vinylpyridine)-functionalized magnetic Al-MOF for the removal of naproxen from aqueous solution. J. Hazard. Mater. 383:121144. doi: 10.1016/j.jhazmat.2019.121144

Lowell, S., Shields, J. E., Thomas, M. A., and Thommes, M. (2004). "Adsorption mechanism," in Characterization of Porous Solids and Powders: Surface Area, Pore Size and Density, eds S. Lowell, J. E. Shields, M. A. Thomas, and M. Thommes (Dordrecht: Springer Netherlands), 15-57. doi: 10.1007/978-1-4020-2303-3_4

Mahmoodi, N. M., Oveisi, M., Taghizadeh, A., and Taghizadeh, M. (2020). Synthesis of pearl necklace-like ZIF-8@chitosan/PVA nanofiber with synergistic effect for recycling aqueous dye removal. Carbohydr. Polym. 227:115364. doi: 10.1016/j.carbpol.2019.115364

Maira, A. J., Yeung, K. L., Soria, J., Coronado, J. M., Belver, C., Lee, C. Y., et al. (2001). Gas-phase photo-oxidation of toluene using nanometer-size TiO2 catalysts. Appl. Cataly. B Environ. 29, 327-336. doi: 10.1016/S0926-3373(00)00211-3

Martinez-Costa, J. I., Leyva-Ramos, R., and Padilla-Ortega, E. (2018). Sorption of diclofenac from aqueous solution on an organobentonite and adsorption of cadmium on organobentonite saturated with diclofenac. Clays Clay Miner. 66, 515-528. doi: 10.1346/CCMN.2018.064119

Moghadam, P. Z., Li, A., Wiggin, S. B., Tao, A., Maloney, A. G. P., Wood, P. A., et al. (2017). Development of a Cambridge structural database subset: a collection of metal-organic frameworks for past, present, and future. Chem. Mater. 29, 2618-2625. doi: 10.1021/acs.chemmater.7b00441

Mohamed, A., Salama, A., Nasser, W. S., and Uheida, A. (2018). Photodegradation of ibuprofen, cetirizine, and naproxen by PAN-MWCNT/TiO2-NH2 nanofiber membrane under UV light irradiation. Environ. Sci. Eur. 30:47. doi: 10.1186/s12302-018-0177-6

Mon, M., Bruno, R., Ferrando-Soria, J., Armentano, D., and Pardo, E. (2018). Metal-organic framework technologies for water remediation: towards a sustainable ecosystem. J. Mater. Chem. A 6, 4912-4947. doi: 10.1039/C8TA00264A

Nakada, N., Shinohara, H., Murata, A., Kiri, K., Managaki, S., Sato, N., et al. (2007). Removal of selected pharmaceuticals and personal care products (PPCPs) and endocrine-disrupting chemicals (EDCs) during sand filtration and ozonation at a municipal sewage treatment plant. Water Res. 41, 4373-4382. doi: 10.1016/j.watres.2007.06.038

Oveisi, M., Asli, M. A., and Mahmoodi, N. M. (2018). MIL-Ti metal-organic frameworks (MOFs) nanomaterials as superior adsorbents: Synthesis and ultrasound-aided dye adsorption from multicomponent wastewater systems. J. Hazard. Mater. 347, 123-140. doi: 10.1016/j.jhazmat.2017.12.057

Poyatos, J. M., MuÒio, M. M., Almecija, M. C., Torres, J. C., Hontoria, E., and Osorio, F. (2010). Advanced oxidation processes for wastewater treatment: state of the art. Water Air Soil Pollut. 205, 187-204. doi: 10.1007/s11270-009-0065-1

Qin, F. X., Jia, S. Y., Liu, Y., Li, H. Y., and Wu, S. H. (2015). Adsorptive removal of bisphenol A from aqueous solution using metal-organic frameworks. Desalination Water Treat. 54, 93-102. doi: 10.1080/19443994.2014.883331

Qiu, S., Xue, M., and Zhu, G. (2014). Metal-organic framework membranes: from synthesis to separation application. Chem. Soc. Rev. 43, 6116-6140. doi: 10.1039/C4CS00159A

Rasheed, T., Bilal, M., Nabeel, F., Adeel, M., and Iqbal, H. M. N. (2019). Environmentally-related contaminants of high concern: potential sources and analytical modalities for detection, quantification, and treatment. Environ. Int. 122, 52-66. doi: 10.1016/j.envint.2018.11.038

Rego, R. M., Kuriya, G., Kurkuri, M. D., and Kigga, M. (2020). MOF based engineered materials in water remediation: recent trends. J. Hazard. Mater. 403:123605. doi: 10.1016/j.jhazmat.2020.123605

Richardson, S. D., and Kimura, S. Y. (2017). Emerging environmental contaminants: challenges facing our next generation and potential engineering solutions. Environ. Tech. Innov. 8, 40-56. doi: 10.1016/j.eti.2017.04.002 
Richardson, S. D., and Ternes, T. A. (2018). Water analysis: emerging contaminants and current issues. Anal. Chem. 90, 398-428. doi: 10.1021/acs.analchem.7b04577

Rodriguez-Narvaez, O. M., Peralta-Hernandez, J. M., Goonetilleke, A., and Bandala, E. R. (2017). Treatment technologies for emerging contaminants in water: a review. Chem. Eng. J. 323, 361-380. doi: 10.1016/j.cej.2017.04.106

Rojas, S., Arenas-Vivo, A., and Horcajada, P. (2019). Metal-organic frameworks: A novel platform for combined advanced therapies. Coord. Chem. Rev. 388, 202-226. doi: 10.1016/j.ccr.2019.02.032

Ruhí, A., Acuña, V., Barceló, D., Huerta, B., Mor, J. R., Rodríguez-Mozaz, S., et al. (2016). Bioaccumulation and trophic magnification of pharmaceuticals and endocrine disruptors in a Mediterranean river food web. Sci. Total Environ. 540, 250-259. doi: 10.1016/j.scitotenv.2015.06.009

Russo, V., Masiello, D., Trifuoggi, M., Di Serio, M., and Tesser, R. (2016). Design of an adsorption column for methylene blue abatement over silica: from batch to continuous modeling. Chem. Eng. J. 302, 287-295. doi: 10.1016/j.cej.2016.05.020

Russo, V., Trifuoggi, M., Di Serio, M., and Tesser, R. (2017). Fluid-solid adsorption in batch and continuous processing: a review and insights into modeling. Chem. Eng. Technol. 40, 799-820. doi: 10.1002/ceat.201600582

Ryu, J., Oh, J., Snyder, S. A., and Yoon, Y. (2014). Determination of micropollutants in combined sewer overflows and their removal in a wastewater treatment plant (Seoul, South Korea). Environ. Monit. Assess. 186, 3239-3251. doi: 10.1007/s10661-013-3613-5

Sann, E. E., Pan, Y., Gao, Z., Zhan, S., and Xia, F. (2018). Highly hydrophobic ZIF8 particles and application for oil-water separation. Sep. Purif. Technol. 206, 186-191. doi: 10.1016/j.seppur.2018.04.027

Seo, P. W., Khan, N. A., Hasan, Z., and Jhung, S. H. (2016). Adsorptive removal of artificial sweeteners from water using metal-organic frameworks functionalized with urea or melamine. ACS Appl. Mater. Interfaces 8, 29799-29807. doi: 10.1021/acsami.6b11115

Stock, N., and Biswas, S. (2012). Synthesis of metal-organic frameworks (mofs): routes to various mof topologies, morphologies, and composites. Chem. Rev. 112, 933-969. doi: $10.1021 / \mathrm{cr} 200304 \mathrm{e}$

Tareq, R., Akter, N., and Azam, M. S. (2019). "Chapter 10 - biochars and biochar composites: low-cost adsorbents for environmental remediation," in Biochar from Biomass and Waste, eds Y. S. Ok, D. C. W. Tsang, N. Bolan, and J. M. Novak (Oxford: Elsevier), 169-209. doi: 10.1016/B978-0-12-811729-3.00010-8

Tariq, M. A., Faisal, M., Muneer, M., and Bahnemann, D. (2007). Photochemical reactions of a few selected pesticide derivatives and other priority organic pollutants in aqueous suspensions of titanium dioxide. J. Mol. Cataly. A 265, 231-236. doi: 10.1016/j.molcata.2006.10.013

Tran, N. H., Reinhard, M., and Gin, K. Y. H. (2018). Occurrence and fate of emerging contaminants in municipal wastewater treatment plants from different geographical regions-a review. Water Res. 133, 182-207. doi: 10.1016/j.watres.2017.12.029

Tranchemontagne, D. J., Hunt, J. R., and Yaghi, O. M. (2008). Room temperature synthesis of metal-organic frameworks: MOF-5, MOF-74, MOF-177, MOF199, and IRMOF-0. Tetrahedron 64, 8553-8557. doi: 10.1016/j.tet.2008.06.036

Trickett, C. A., Helal, A., Al-Maythalony, B. A., Yamani, Z. H., Cordova, K. E., and Yaghi, O. M. (2017). The chemistry of metal-organic frameworks for $\mathrm{CO} 2$ capture, regeneration and conversion. Nat. Rev. Mater. 2:17045. doi: 10.1038 /natrevmats.2017.45

Vieno, N. M., Härkki, H., Tuhkanen, T., and Kronberg, L. (2007). Occurrence of pharmaceuticals in river water and their elimination in a pilot-scale drinking water treatment plant. Environ. Sci. Technol. 41, 5077-5084. doi: $10.1021 /$ es $062720 \mathrm{x}$

Wang, C. C., Wang, X., and Liu, W. (2020). The synthesis strategies and photocatalytic performances of $\mathrm{TiO} / \mathrm{MOF}$ composites: a state-of-the-art review. Chem. Eng. J. 391:123601. doi: 10.1016/j.cej.2019.123601
Wang, Q., Gao, Q., Al-Enizi, A. M., Nafady, A., and Ma, S. (2020). Recent advances in MOF-based photocatalysis: environmental remediation under visible light. Inorg. Chem. Front. 7, 300-339. doi: 10.1039/C9QI0 $1120 \mathrm{~J}$

Wang, Z., Huang, J., Mao, J., Guo, Q., Chen, Z., and Lai, Y. (2020). Metal-organic frameworks and their derivatives with graphene composites: preparation and applications in electrocatalysis and photocatalysis. J. Mater. Chem. A 8, 2934-2961. doi: 10.1039/C9TA12776C

Westerhoff, P., Yoon, Y., Snyder, S., and Wert, E. (2005). Fate of endocrinedisruptor, pharmaceutical, and personal care product chemicals during simulated drinking water treatment processes. Environ. Sci. Technol. 39, 6649-6663. doi: 10.1021/es0484799

Wu, Z., Yuan, X., Zhong, H., Wang, H., Zeng, G., Chen, X., et al. (2016). Enhanced adsorptive removal of p-nitrophenol from water by aluminum metalorganic framework/reduced graphene oxide composite. Sci. Rep. 6:25638. doi: $10.1038 /$ srep 25638

Xu, P., Drewes, J. E., Bellona, C., Amy, G., Kim, T. U., Adam, M., et al. (2005). Rejection of emerging organic micropollutants in nanofiltrationreverse osmosis membrane applications. Water Environ. Res. 77, 40-48. doi: 10.2175/106143005X41609

Yaghi, O. M., Kalmutzki, M. J., and Diercks, C. S. (2019). Liquid- and Gas-Phase Separation in MOFs. Introd. Reticular Chem. 365-393. doi: 10.1002/9783527821099.ch16

Yaghi, O. M., Li, G., and Li, H. (1995). Selective binding and removal of guests in a microporous metal-organic framework. Nature 378, 703-706. doi: 10.1038/378703a0

Yang, D., and Gates, B. C. (2019). Catalysis by metal organic frameworks: perspective and suggestions for future research. ACS Catal. 9, 1779-1798. doi: 10.1021/acscatal.8b04515

Yang, M., and Bai, Q. (2019). Flower-like hierarchical Ni-Zn MOF microspheres: Efficient adsorbents for dye removal. Colloids Surf. A 582:123795. doi: 10.1016/j.colsurfa.2019.123795

Yang, S. J., Kim, T., Im, J. H., Kim, Y. S., Lee, K., Jung, H., et al. (2012). MOF-derived hierarchically porous carbon with exceptional porosity and hydrogen storage capacity. Chem Mater. 24, 464-470. doi: 10.1021/cm20 $2554 \mathrm{j}$

Yu, J., Xiong, W., Li, X., Yang, Z., Cao, J., Jia, M., et al. (2019). Functionalized MIL-53(Fe) as efficient adsorbents for removal of tetracycline antibiotics from aqueous solution. Micropor. Mesopor. Mater. 290:109642. doi: 10.1016/j.micromeso.2019.1 09642

Zhao, R., Ma, T., Zhao, S., Rong, H., Tian, Y., and Zhu, G. (2020). Uniform and stable immobilization of metal-organic frameworks into chitosan matrix for enhanced tetracycline removal from water. Chem. Eng. J. 382:122893. doi: 10.1016/j.cej.2019.122893

Zhao, Z., Ma, X., Kasik, A., Lin, Y. S., and Li, Z. (2013). Gas separation properties of metal organic framework (MOF-5) membranes. Ind. Eng. Chem. Res. 52, 1102-1108. doi: $10.1021 /$ ie202777q

Conflict of Interest: The authors declare that the research was conducted in the absence of any commercial or financial relationships that could be construed as a potential conflict of interest.

Copyright (c) 2020 Russo, Hmoudah, Broccoli, Iesce, Jung and Di Serio. This is an open-access article distributed under the terms of the Creative Commons Attribution License (CC BY). The use, distribution or reproduction in other forums is permitted, provided the original author(s) and the copyright owner $(s)$ are credited and that the original publication in this journal is cited, in accordance with accepted academic practice. No use, distribution or reproduction is permitted which does not comply with these terms. 